\title{
Prospective payment system and racial/ ethnic disparities: a national retrospective observational study in anaemia complication among end-stage renal disease patients in the US
}

\author{
Nga TQ. Nguyen * (D), Alexander P. Maxwell, Michael Donnelly and Ciaran O’Neill
}

\begin{abstract}
Background: A series of policy changes in 2011 altered reimbursement arrangements and guidance on use of erythropoiesis-stimulating agents for end-stage renal disease (ESRD) patients with anaemia in the US. While the policy changes were principally directed at care delivered in an outpatient setting, these had the potential to affect inpatient care also. This study used HCUP-NIS data (2008-2016) to examine trends in recorded anaemia among ESRD hospitalizations and analyse disparities in inpatient outcomes among ethnic groups following policy changes.

Methods: The International Classification of Diseases codes were used to identify ESRD admissions, recorded anaemia due to chronic kidney disease (CKD), and to generate an age-adjusted Deyo-Charlson comorbidity index. Linear splines with a knot placed at the time point of policy changes and multivariable logistic regression were used to examine the likelihood of recorded anaemia, adjusted for a range of socio-demographic and clinical covariates. Difference-in-difference analyses investigated the impact of policies on recorded anaemia. Other outcomes included hospital cost, mortality and place of discharge.

Results: The percentage of inpatient episodes with recorded anaemia arising from CKD increased from 26.2\% in 2008 to $50.0 \%$ in 2016. Anaemia was more likely to be recorded as a complication of ESRD among minority ethnic groups and Native American admissions, in particular, (OR 1.20,95\% Cl 1.15-1.25) relative to White American admissions; and these disparities widened following changes to reimbursement. Minorities were less likely to die in hospital and to be discharged to another healthcare facility, and (with the exception of Black American admissions) they were more expensive to treat.
\end{abstract}

Conclusions: Our findings provide evidence of an increase in recorded anaemia consistent with a shift of patients from outpatient to inpatient settings in the wake of changes to reimbursement enacted in 2011. In addition, the study highlights the existence of ethnic disparities that widened after the policy initiated reimbursement changes.

Keywords: Anaemia, end-stage renal disease, Racial/ethnic disparities, Prospective payment system

\footnotetext{
* Correspondence: nnguyen05@qub.ac.uk

Centre for Public Health, School of Medicine, Dentistry and Biomedical

Sciences, Queen's University Belfast, Belfast, UK
} 


\section{Background}

End-stage renal disease (ESRD) affected more than half a million people in the United States (US) in 2016 and is associated with a significant economic burden [1]. Anaemia is among the most commonly diagnosed modifiable complications of chronic kidney disease (CKD) and is more pronounced in later stages of the disease [2]. Anaemia is associated with higher risks for the development of left ventricular hypertrophy, heart failure [3], cognitive impairment [4], and poorer quality of life [5]; it is also an important predictor of mortality [6].

The pathogenesis of anaemia in CKD is multifactorial but the central problem is reduced erythropoietin production by the kidneys [2, 7]. While erythropoiesisstimulating agents (ESAs) remain the first-line treatment for anaemia, serious concerns about their safety have been raised [8], and helped prompt policy changes related to their use in the US [9]. In 2011, a series of policy changes adopted in the US combined to change incentives around the use of ESAs. The Medicare ESRD prospective payment system (PPS) implemented in 2011 altered financial incentives by allowing providers to retain payments above Medicare's reimbursement level while providing dialysis services. This reduced the incentive to provide treatments formerly reimbursed on a feefor-service basis notably injectable medications such as ESAs [9]. In the same year, the US Food and Drug Administration (FDA) revised the prescribing advice for ESAs with guidance on a more conservative use of ESAs for renal anaemia [10]. Also in 2011 the ESRD Quality Incentive Payment was implemented [11]. This program aimed to raise care quality by imposing a penalty for poor management of dialysis patients including the overuse of ESAs [11]. These three policy changes altered the financial context in which anaemia was managed principally in an outpatient setting. All constrained the use of ESAs. Hereafter these changes are for convenience referred to as PPS. While there is some evidence that the policy changes resulted in shift in transfusions from an outpatient to an inpatient setting [12], their effect on care and outcomes in an inpatient setting more generally have not to our knowledge been examined.

Race/ethnicity adds a layer of complexity to the potential impact of these policy changes. Ethnicity has been shown to be predictive of anaemia [5] and while ethnic disparities have been well documented in the literature for Black and White Americans [13, 14], there is limited evidence on the comparative experience of other ethnic groups or what impact the changing policy context has had in respect of them. This may be due in part to the smaller numbers of specific groups such as Native Americans who might appear in survey data [5]) or a lack of life tables for these populations [15]. These groups also experience economic disadvantage [16] and with regard to Native Americans, have the poorest renal outcomes and highest age-adjusted prevalence of diagnosed diabetes among the various ethnic groups [17]. Therefore, an examination of their specific experience may be insightful. The aim of this study was to investigate the impact of PPS on the likelihood of an inpatient episode for ESRD being recorded with anaemia following the adoption of PPS as well as its effect on hospital costs, inpatient mortality and discharge destination. A secondary aim was to examine the impact of PPS on ethnic disparities with a particular focus on the experience of Native Americans.

\section{Methods}

\section{Data sources}

Data were obtained from the National (Nationwide) Inpatient Sample - Healthcare Cost and Utilization Project (HCUP-NIS), Agency for Healthcare Research and Quality (AHRQ) [18]. HCUP-NIS is the largest all-payer inpatient care database in the US representing an approximately $20 \%$ sample of discharges from all HCUP community hospitals, excluding rehabilitation and longterm acute care hospitals in the US. HCUP-NIS data contains over 7 million hospital admissions annually, which represents over 35 million hospitalizations every year in the US [18]. We pooled 9 years data (2008-2016) to increase sample size and permit analyses of policy changes.

The International Classification of Diseases 9th and 10th Revision (ICD9 and ICD10) codes were used to identify all admissions with a primary diagnosis of ESRD (ICD9 585.6, ICD10 N18.6) and a procedure/diagnosis code referring to any type of renal replacement therapy (RRT, comprising: haemodialysis, peritoneal dialysis and kidney transplantation). Episodes with a diagnosis code of acute kidney injury (ICD9 584.x, ICD10 N17.x) were excluded from study because they represented a distinct patient cohort [19]. From this cohort, episodes that involved anaemia due to CKD were identified using ICD codes. Additional file 1 (Table S1) provides details on ICD9 and ICD10 codes used. An Age-adjusted DeyoCharlson Comorbidity Index (ACCI) was developed based on ICD codes for each patient's episode of care [20]. We also determined iron deficiency status using ICD codes for inclusion in analyses.

\section{Data analyses}

Sample characteristics were summarized using mean and standard deviation (SD) for continuous variables and proportions for categorical variables. Ethnicities were grouped into six categories: White, Black, Hispanic, Asian, Native American and Others based on data in HCUP-NIS. 
To examine the impact of PPS on anaemia outcome, we stratified our sample by two periods: before PPS (2008 to 2010) and after PPS (2011 to 2016) [21]. Linear splines with one knot placed at 2011 and logistic regression models were used to estimate trends over time taking the timing of PPS into account. This was consistent with previous studies $[12,21]$ and an preliminary examination of our data (Fig. S1, Additional file). Models were adjusted for a range of socio-demographic (insurance type, gender, age at admission, median household income for patient's ZIP Code and location -broadly in terms of rurality), and clinical variables (renal replacement therapies, iron deficiency, comorbidity score ACCI, hospital characteristics, proteinuria, diabetes with or without complications) (see Additional file 1 for more details).

Marginal effects were used to estimate the trend in recorded anaemia across ethnicities, gender, type of RRT, income quartiles and type of insurance over the 9-year period. A difference-in-difference analysis was conducted by using marginal effects to estimate the gap between White Americans and other races/ethnicities before and after the adoption of PPS.

To examine the potential for PPS's effect to extend more deeply into inpatient care, we examined the likelihood of inpatient mortality and discharge to a healthcare facility among those admitted with a primary diagnosis of ESRD using multivariable logistic regression. Discharge destination included routine discharge and discharge to healthcare facilities (including longterm care facilities or care homes, short-term hospitals, home healthcare and other rehabilitation centers), excluding those who died at the hospital. Models were adjusted for socio-demographic and clinical variables. Charges were converted to costs using the 'cost-tocharge' ratio tool provided by AHRQ-HCUP. Hospital costs were then adjusted for inflation using the personal consumption expenditure health component price index based on its ability to capture information on expenditures by all payers [22]. Generalized linear models (GLM) were used to accommodate the continuous, positive and skewed nature of hospital cost data in the cost analysis. Akaike information criterion and Bayesian information criterion were used to assess the fit of the GLM model [23].

\section{Sensitivity analyses}

In order to generate national estimates using HCUP-NIS data that span multiple years, we conducted a sensitivity analysis with all models weighted by trend weight for data years prior to 2012 and by the discharge-level weight for data years 2012 and later as recommended by the AHRQ [18].

\section{Results}

\section{Characteristics of study population}

Among 591,683 admissions with ESRD over a 9-year period, the proportion of episodes of care related to White, Native, Black, Asian, and Hispanic Americans were $39.8,0.95,36.6,3.4$, and $16.4 \%$ respectively (Table 1). The percentage of inpatient episodes with recorded anaemia arising from CKD increased from $26.2 \%$ in 2008 to $50.0 \%$ in 2016 .

The mean age at admission ranged from 57.0 ( \pm 15.7) for Black American admissions to $64.8( \pm 15.7)$ for Asian American admissions. Medicare was the predominant type of insurance while only a small percentage had private insurance in each racial group, with the smallest number observed in Native American admissions (7.1\%). A higher percentage of Native American admissions were from smaller sized communities compared to other ethnicities. More than half of Native American and Black American admissions lived in areas included in the lowest quartile of median income.

Regarding the modality of RRT, a large proportion of the sample received haemodialysis with the highest percentage observed among Black (92.8\%) followed by Native American admissions (92.5\%). Diabetes was most prevalent in admissions who were Native Americans with 42.7 and $29.2 \%$ of them having diabetes with and without complications, respectively. Approximately $42.3 \%$ of episodes among Native Americans and 37.8\% of those among Whites with ESRD had anaemia recorded as a diagnosis.

\section{Disparities in recorded anaemia}

Ethnicity remained a strong predictor of anaemia as a recorded complication after controlling for a range of demographic, socioeconomic and clinical factors (Table 2). In the fully adjusted model, compared to admissions who were White Americans, the odds of anaemia was highest for those who were Native Americans (OR 1.20, 95\%CI 1.15-1.25), and Asians (OR 1.20, 95\% CI 1.17-1.22), followed by Hispanics (OR 1.12, 95\%CI 1.10-1.13) and Blacks (OR 1.04, 95\%CI 1.031.05). Admissions who had iron deficiency, diabetes with complications, lower ACCI score, who were aged less than 50 years or more than 80 years had a higher risk of anaemia compared to other groups (Additional file 1, Table S2).

Figures 1 depicts the likelihood of being diagnosed with anaemia over the 9-year period across ethnicity. The overall trend is consistent across all comparisons: all ethnicities have a higher likelihood of anaemia than White Americans admissions and there is a sharp increase in the likelihood of anaemia for all ethnicities in 2011 followed by a steady increment 
Table 1 Descriptive statistics of the pooled sample from 2008 to $2016(N=591,683)$

\begin{tabular}{|c|c|c|c|c|c|c|c|c|c|c|}
\hline & \multicolumn{2}{|c|}{$\begin{array}{l}\text { White American } \\
(n=235,227)\end{array}$} & \multicolumn{2}{|c|}{$\begin{array}{l}\text { Native American } \\
(n=5621)\end{array}$} & \multicolumn{2}{|c|}{$\begin{array}{l}\text { Black American } \\
(n=216,784)\end{array}$} & \multicolumn{2}{|c|}{$\begin{array}{l}\text { Asian American } \\
(n=20,342)\end{array}$} & \multicolumn{2}{|c|}{$\begin{array}{l}\text { Hispanic American } \\
(n=97,220)\end{array}$} \\
\hline & $\mathrm{N}$ & $\%$ & $\mathrm{~N}$ & $\%$ & $\mathbf{N}$ & $\%$ & $\mathbf{N}$ & $\%$ & $\mathrm{~N}$ & $\%$ \\
\hline Female & 108,233 & 46.0 & 3131 & 55.7 & 113,531 & 52.4 & 10,293 & 50.6 & 47,310 & 48.7 \\
\hline Age at admission (Mean SD) & 64.2 & 15.9 & 58.0 & 14.7 & 57.0 & 15.7 & 64.8 & 15.7 & 57.5 & 16.4 \\
\hline \multicolumn{11}{|l|}{ Insurance type } \\
\hline Medicare & 192,021 & 81.6 & 4346 & 77.3 & 165,094 & 76.2 & 14,701 & 72.3 & 61,433 & 63.2 \\
\hline Medicaid & 12,233 & 5.2 & 658 & 11.7 & 29,473 & 13.6 & 2824 & 13.9 & 20,835 & 21.4 \\
\hline Private insurance & 26,433 & 11.2 & 400 & 7.1 & 17,696 & 8.2 & 2223 & 10.9 & 8208 & 8.4 \\
\hline Others & 4540 & 1.9 & 217 & 3.9 & 4521 & 2.1 & 594 & 2.9 & 6744 & 6.9 \\
\hline \multicolumn{11}{|l|}{ Location } \\
\hline Central counties & 55,501 & 23.6 & 1201 & 21.4 & 102,810 & 47.4 & 11,910 & 58.6 & 53,108 & 54.6 \\
\hline Large metro & 63,697 & 27.1 & 581 & 10.3 & 45,326 & 20.9 & 3938 & 19.4 & 13,844 & 14.2 \\
\hline Medium metro & 48,347 & 20.6 & 968 & 17.2 & 32,097 & 14.8 & 3247 & 16.0 & 20,148 & 20.7 \\
\hline Small metro & 24,072 & 10.2 & 690 & 12.3 & 15,787 & 7.3 & 619 & 3.0 & 4954 & 5.1 \\
\hline Micropolitan & 26,629 & 11.3 & 1199 & 21.3 & 13,019 & 6.0 & 561 & 2.8 & 3724 & 3.8 \\
\hline Not metropolitan or Micropolitan & 16,981 & 7.2 & 982 & 17.5 & 7745 & 3.6 & 67 & 0.3 & 1442 & 1.5 \\
\hline \multicolumn{11}{|c|}{ Median household income for patient's ZIP Code ${ }^{a}$} \\
\hline First quartile & 63,311 & 26.9 & 3039 & 54.1 & 118,330 & 54.6 & 3338 & 16.4 & 43,100 & 44.3 \\
\hline Second quartile & 65,208 & 27.7 & 1368 & 24.3 & 45,241 & 20.9 & 4065 & 20.0 & 23,166 & 23.8 \\
\hline Third quartile & 59,311 & 25.2 & 846 & 15.1 & 33,093 & 15.3 & 5766 & 28.4 & 20,292 & 20.9 \\
\hline Fourth quartile & 47,397 & 20.2 & 368 & 6.6 & 20,120 & 9.3 & 7173 & 35.3 & 10,662 & 11.0 \\
\hline Elective admission & 21,180 & 9.0 & 495 & 8.8 & 12,859 & 5.9 & 1208 & 5.9 & 6664 & 6.9 \\
\hline ACCI (Mean SD) & 6.4 & 2.5 & 5.7 & 2.2 & 5.6 & 2.4 & 6.4 & 2.5 & 5.6 & 2.4 \\
\hline \multicolumn{11}{|l|}{ RRT modality } \\
\hline Transplantation & 13,443 & 5.7 & 214 & 3.8 & 7379 & 3.4 & 1107 & 5.4 & 3878 & 4.0 \\
\hline Hemodialysis & 208,911 & 88.8 & 5197 & 92.5 & 201,176 & 92.8 & 18,140 & 89.2 & 89,591 & 92.2 \\
\hline Peritoneal analysis & 12,873 & 5.5 & 210 & 3.7 & 8229 & 3.8 & 1095 & 5.4 & 3751 & 3.9 \\
\hline \multicolumn{11}{|l|}{ Diabetes without complications } \\
\hline Yes & 59,358 & 25.2 & 1642 & 29.2 & 58,213 & 26.9 & 5792 & 28.5 & 28,333 & 29.1 \\
\hline \multicolumn{11}{|l|}{ Diabetes with complications } \\
\hline Yes & 64,978 & 27.6 & 2398 & 42.7 & 51,406 & 23.7 & 6839 & 33.6 & 33,745 & 34.7 \\
\hline \multicolumn{11}{|l|}{ Anaemia due to CKD } \\
\hline Yes & 88,791 & 37.8 & 2380 & 42.3 & 83,310 & 38.4 & 8730 & 42.9 & 40,428 & 41.6 \\
\hline \multicolumn{11}{|l|}{ Iron deficiency } \\
\hline Yes & 4331 & 1.8 & 93 & 1.7 & 4027 & 1.9 & 346 & 1.7 & 1741 & 1.8 \\
\hline \multicolumn{11}{|l|}{ Die during hospitalization } \\
\hline Yes & 5123 & 2.2 & 67 & 1.2 & 2459 & 1.1 & 351 & 1.7 & 1120 & 1.2 \\
\hline \multicolumn{11}{|l|}{ Discharge destination: Health care facility } \\
\hline Yes & 96,895 & 41.2 & 1460 & 26.0 & 69,638 & 32.1 & 6482 & 31.9 & 25,214 & 25.9 \\
\hline \multicolumn{11}{|l|}{ Hospital characteristics } \\
\hline Private hospital & 189,042 & 80.4 & 4596 & 81.8 & 168,488 & 77.7 & 16,140 & 79.3 & 74,132 & 76.3 \\
\hline Hospital in urban area & 192,126 & 81.7 & 4262 & 75.8 & 181,126 & 83.6 & 17,970 & 88.3 & 85,945 & 88.4 \\
\hline Teaching hospital & 109,764 & 46.7 & 2674 & 47.6 & 124,544 & 57.5 & 10,127 & 49.8 & 48,633 & 50.0 \\
\hline
\end{tabular}


Table 2 Relative likelihood of inpatient CKD-related anaemia among ESRD admissions by ethnicity

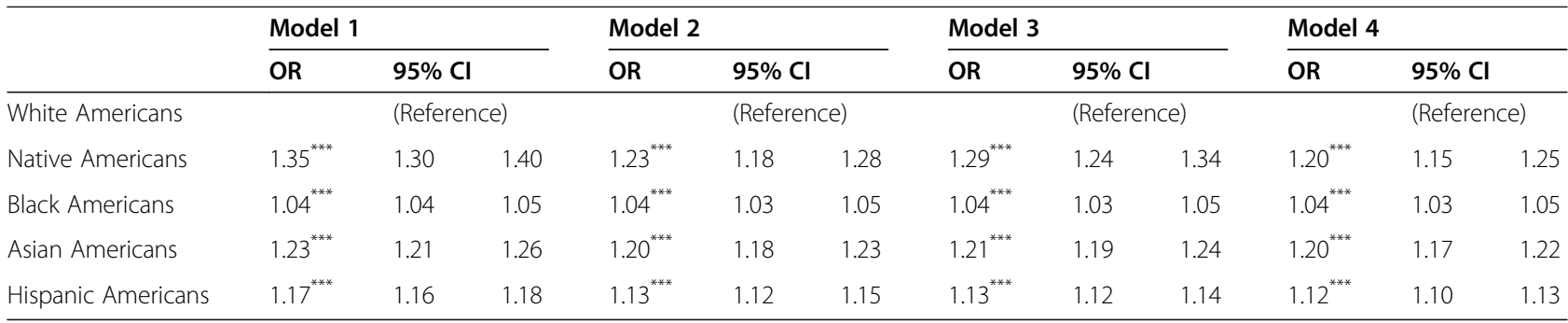

Note: Model 1: unadjusted model logistic regression model. Model 2, 3, 4: linear splines with one knot placed at 2011 and logistic regression models. Model 2: adjusted for demographic and socioeconomic variables (insurance type, gender, age at admission, median household income for patient's ZIP Code, location). Model 3: adjusted for clinical variables (renal replacement therapies, iron deficiency, proteinuria, age adjusted comorbidity score ACCl, hospital characteristics, diabetes with or without complications). Model 4: fully adjusted model for all demographic, socioeconomic and clinical variables.* $p<0.05$, ${ }^{* *} p<0.01,{ }^{* * *} p<$ 0.001. Cl - Confidence intervals

afterwards (Fig. 1). Comparisons across gender, type of RRT, income quartile and type of insurance groups are presented in Additional file 1 (Fig. S2). Those admissions whose RRT were via transplantation had a lower likelihood of anaemia compared to those on haemodialysis; those with private insurance or Medicare had the lowest predicted probability of anaemia followed by those on Medicaid and then other types of insurance.

\section{The impact of PPS on recorded anaemia}

Linear splines with a knot placed at 2011 and logistic regression analysis were used to investigate the impact of PPS on anaemia outcome. Results from the fully adjusted regression model showed that the odds of recorded anaemia after PPS was 1.42 (95\%CI: 1.40-1.44) compared to the preceding period. Difference in difference (DiD) analysis - looking at the experience of specific races/ethnicities over different periods - combined

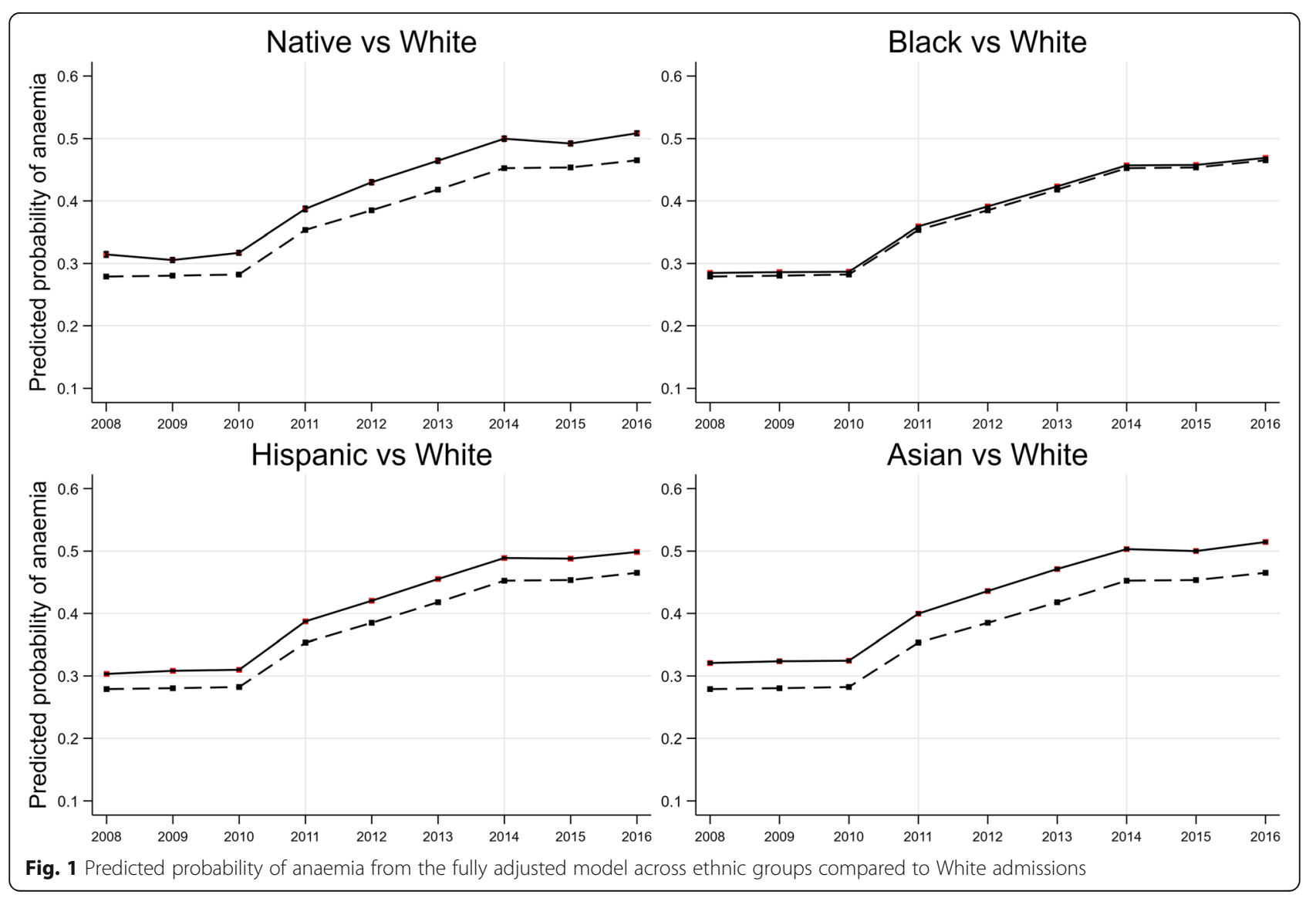


with marginal effect analysis revealed that the changes in the difference between racial groups before and after the introduction of PPS were significant, where the gap was most evident for admission who were Native Americans and Asian Americans (Table 3). For example, before PPS, the probability of recorded anaemia was 3.67\% higher in Native American admissions relative to White American admissions. This difference increased in the following periods by $0.57 \%$ (95\%CI: $0.42-0.72 \%, p<$ $0.001)$ to $4.25 \%$.

\section{Inpatient mortality, discharge destination, and hospital costs}

In the wake of PPS, the odds of inpatient mortality for admissions with anaemia compared to admissions without anaemia increased; the odds ratio for admissions with anaemia dying in hospital rose from 0.61 (95\%CI: $0.56-0.67)$ to 0.72 (95\%CI: $0.68-0.76)$ between 2008 and 2010 and 2011-2016 (Table 4). The likelihood of discharge to another healthcare facility increased, and costs per inpatient episode fell (Table 4). Minorities including Native American admissions were less likely to die in hospital, less likely to be discharged to another healthcare facility and were more expensive to treat (with the exception of Black American admissions who had lower costs) (Table 5).

\section{Sensitivity analyses}

Results from sensitivity analyses in which HCUP weights are applied to the sample are presented in Additional file 1 (Table S3). It is evident that after being weighted using HCUP weights, ethnic disparities between admission who were Whites and other ethnicities remained significant with the highest ORs observed in Native American, followed by Asian, Hispanic and Black American admissions. The sensitivity analysis results were almost identical compared to the main results with regards to ethnic groups.

\section{Discussion}

We found that anaemia as a recorded complication of ESRD in an inpatient setting increased significantly in the wake of the introduction of PPS in 2011 and has continued on an upward trend thereafter. The findings are consistent with those of Wetmore et al. (2016) in respect of transfusions in the sense that the structural break in 2011 may have been associated with a shift in the delivery of care for this patient group from an outpatient to an inpatient setting [12]. As can be seen in Table 4, while the fall in per patient costs has attenuated the increased financial burden associated with the management of anaemia in this setting this has been more than offset by the increased numbers being treated.

Ethnicity was a strong predictor of recorded anaemia due to CKD among ERSD inpatients. Other studies also found that Blacks [5, 24] and Hispanics [5] had significantly higher odds of anaemia compared to Whites. However, we found the disparity experienced by Native American admissions was greater than that of any other ethnic group. A review in 2011 found that anaemia was a public health problem among indigenous populations internationally [25]. While iron deficiency is the most common cause of anaemia in the US, iron deficiency prevalence has been reported to be 10-times higher among Native Americans [26]. Other studies found that Native Americans might be more likely to suffer anaemia as a result of delayed treatment, or poorer selfcare [27]. As complications of ESRD are inter-related and due to the chronicity of the disease, whether Native Americans could have more complications other than anaemia (i.e. bone and mineral disorders, malnutrition, metabolic acidosis) requires further research.

While sharper disparities in terms of magnitude with respect to cost between ethnicities were observed (Table 5), the interpretation of these results require caution. Costs reflect length of stay and the procedures associated with an admission, and these entities may be influenced by disease severity and case complexity. Unfortunately, HCUP provided limited data with respect to severity/complexity though the observation that nonWhite admissions had a higher percentage of diabetes and diabetes with complications is consistent with greater complexity and higher costs (see Table 1). Moreover, we found that admissions with anaemia were less likely to die in the hospital compared to those without this condition. Given the data available we can only

Table 3 Impact of policy on racial disparities

\begin{tabular}{lllll}
\hline & Before PPS & After PPS & Difference in difference & $\mathbf{9 5 \% C l}$ \\
\hline White Americans & Reference & & & $0.42-0.72 \%$ \\
Native Americans & $3.67 \%$ & $4.25 \%$ & $0.57 \%^{* * *}$ & $0.02-0.12 \%$ \\
Black Americans & $0.40 \%$ & $0.48 \%$ & $0.07 \%^{* * *}$ & $0.50-0.67 \%$ \\
Asian Americans & $3.74 \%$ & $4.33 \%$ & $0.59 \%^{* * *}$ & $0.30-0.42 \%$ \\
Hispanic Americans & $2.08 \%$ & $2.44 \%$ & $0.36 \%^{* * *}$ & \\
\hline
\end{tabular}

Note: This table presents the marginal effect analysis results from Model 4 (Table 2 ) in form of incremental probability of having recorded anaemia of different ethnicities vs White Americans. ${ }^{* *} p<0.001$ 
Table 4 Changes in key outcomes before and after PPS adoption

\begin{tabular}{|c|c|c|c|c|c|c|}
\hline & \multicolumn{3}{|l|}{ Before PPS } & \multicolumn{3}{|l|}{ After PPS } \\
\hline & $\mathrm{N}(\%)$ & $p$-value ${ }^{\Phi}$ & OR & $\mathrm{N}(\%)$ & $p$-value ${ }^{\Phi}$ & OR \\
\hline \multicolumn{7}{|c|}{ Inpatient mortality ${ }^{a}$} \\
\hline No anaemia ${ }^{a}$ & $2594(2.1)$ & & Ref & $3993(1.68)$ & & Ref \\
\hline Anaemia $^{\beta}$ & $645(1.29)$ & $* * *$ & $0.61^{* * *}(0.56-0.67)$ & $2160(1.2)$ & $* * *$ & $0.72^{* * *}(0.68-0.76)$ \\
\hline \multicolumn{7}{|c|}{ Discharge to a healthcare facility ${ }^{b}$} \\
\hline No anaemia ${ }^{a}$ & $41,606(35.3)$ & & Ref & $83,812(36.7)$ & & Ref \\
\hline \multirow[t]{2}{*}{ Anaemia $^{\beta}$} & $16,150(33.4)$ & $* * *$ & $0.93^{* * *}(0.91-0.95)$ & $63,387(36.5)$ & 0.30 & $1.00(1.00-1.02)$ \\
\hline & Mean (SD) & $p$-value ${ }^{*}$ & Marginal effects & Mean (SD) & $p$-value ${ }^{*}$ & Marginal effects \\
\hline \multicolumn{7}{|c|}{ Hospital cost (2016 USD) ${ }^{c}$} \\
\hline No anaemia & $11,565(14623)$ & & Ref & $10,859(14454)$ & & Ref \\
\hline Anaemia & $11,352(13032)$ & $* *$ & $768^{* * *}(654-882)$ & $10,790(12480)$ & 0.11 & $683^{* * *}(615-752)$ \\
\hline \multicolumn{7}{|c|}{$\begin{array}{l}\text { Note: }{ }^{\text {ab, }, c} \text { All models were adjusted for demographic and socioeconomic variables (insurance type, gender, age at admission, median household income for } \\
\text { patient's ZIP Code, location), clinical variables (renal replacement therapies, iron deficiency, proteinuria, age adjusted comorbidity score ACCI, hospital } \\
\text { characteristics, diabetes with or without complications), and year of admission. }{ }^{a} \text { Logistic regression model; }{ }^{b} \text { Logistic regression model, restricted to admissions } \\
\text { who were alive at discharge, }{ }^{c} \text { Generalized linear models, additionally adjusted for inpatient mortality. OR: odds ratio, } 95 \% \text { Cl: } 95 \% \text { confidence interval. Marginal } \\
\text { effect estimates are presented in form of incremental/decremented hospital cost. }{ }^{a} \text { The number (percentage) of admissions who died in hospitals/were discharged } \\
\text { to a healthcare facility and who did not have anaemia diagnosis, }{ }^{\beta} \text { The number (percentage) of admissions who died in hospitals/were discharged to a healthcare } \\
\text { facility and who had anaemia diagnosis. }{ }^{\Phi} \text { Chi square test, }{ }^{*} \text { Independent sample T-test. Ref: reference group. }{ }^{*} p<0.05,{ }^{* *} p<0.01,{ }^{* * *} p<0.001\end{array}$} \\
\hline
\end{tabular}

speculate as to what may explain this seemingly counter intuitive result. It is possible that those with a diagnosis of anaemia are more closely monitored/aggressively managed by staff. It is also possible that an element of selection bias results in a group of relatively healthy patients who would formerly have been adequately managed in ambulatory care now be transferred to inpatient care with more positive outcomes. This is an area that warrants further research.

The linear splines analysis highlighted the response among ESRD inpatients to policy changes (Fig. 1 and Table 3). There was an evident upward trend in the prevalence of recorded anaemia after the 2011. Thamer et al. (2014) also reported that major declines in ESAs doses were observed in most large dialysis providers in the US due to the confluence of financial incentives bundling payment for these medications in the first year after PPS [28]. Although Turenne et al. (2015) found no meaningful differences by race/ethnicity regarding the rates of change of management practices or laboratory measures in anaemia after PPS, this study was conducted in a comparatively short window (17 months) during which effects might not be evident [21]. Moreover, during the study period (2008-2016), the standardised incidence of ESRD among White Americans stabilized while it decreased slightly for Black and Native Americans (though remained 2.9 and 1.2 times higher compared to Whites) [1]. However, given the welcoming decrease in incidence, the increased likelihood of anaemia found among Native Americans after policy changes warrants further research.

Our study has shown that the adoption of policies intended to manage the use of ESAs might have unintended consequences such as changes in resource use

Table 5 Racial disparities in inpatient mortality, discharge destination, and hospital costs among ESRD admissions

\begin{tabular}{|c|c|c|c|c|c|c|}
\hline & \multicolumn{2}{|c|}{ Inpatient mortality ${ }^{a}$} & \multicolumn{2}{|c|}{ Discharge to a health facility ${ }^{b}$} & \multicolumn{2}{|c|}{ Hospital cost (2016 USD) ${ }^{c}$} \\
\hline & OR & $95 \% \mathrm{Cl}$ & OR & $95 \% \mathrm{Cl}$ & Marginal effects & $95 \% \mathrm{Cl}$ \\
\hline White Americans & Ref & & Ref & & Ref & \\
\hline Native Americans & $0.78^{*}$ & $0.61-0.99$ & $0.59^{* * *}$ & $0.55-0.63$ & $364^{*}$ & 82 to 646 \\
\hline Black Americans & $0.77^{* * *}$ & $0.73-0.81$ & $0.89^{* * *}$ & $0.88-0.90$ & $-142^{* * *}$ & -212 to -72 \\
\hline Asian Americans & $0.88^{*}$ & $0.79-0.99$ & $0.60^{* * *}$ & $0.58-0.62$ & $1394^{* * *}$ & 1221 to 1567 \\
\hline Hispanic Americans & $0.81^{* * *}$ & $0.75-0.86$ & $0.61^{* * *}$ & $0.60-0.63$ & 20 & -71 to 113 \\
\hline
\end{tabular}

Note:: ${ }^{a, b, c}$ All models were adjusted for demographic and socioeconomic variables (insurance type, gender, age at admission, median household income for patient's ZIP Code, location), clinical variables (renal replacement therapies, iron deficiency, proteinuria, age adjusted comorbidity score ACCl, hospital characteristics, diabetes with or without complications. ${ }^{\mathrm{a}, \mathrm{b}, \mathrm{c}}$ Spline models with one knot placed at 2011 and ${ }^{\mathrm{a}}$ Logistic regression model; ${ }^{\mathrm{b}}$ Logistic regression model, restricted to admissions who were alive at discharge, ${ }^{c}$ Generalized linear models, additionally adjusted for inpatient mortality. OR: odds ratio, $95 \%$ Cl: $95 \%$ confidence interval. Marginal effect estimates are presented in form of incremental/decremented hospital cost of different ethnicities vs White Americans. Ref: reference group. ${ }^{*} p<0.05,{ }^{* *} p<0.01,{ }^{* * *} p<0.001$ 
and where care is delivered. Our study demonstrates an increase in episodes of care for such patients in an inpatient setting and a widening of ethnic disparities in such care. The reduction in cost and increase in mortality suggest changes in intensity of care and outcomes experienced by the patient cohort being admitted to hospital. Studying such changes is important in ascertaining the affect across the system of policy changes whose principle effect may be elsewhere.

\section{Limitations}

There are a number of limitations to our study. Firstly, there has been a significant increase in the number of individuals identified as "mixed race" in the US [13]. That said, self-identified race/ethnicity is a strong predictor of both self-rated health and health outcomes $[5,24]$. Secondly, there has been debate related to the use of ICD codes to identify health status [29]. It remains the case, however, that these are internationally recognized classifications, that are widely used [30]. Thirdly, outpatient data is not collected on the same annual basis as inpatient data by AHRQ. It was not therefore possible to examine trends in an outpatient setting or the effect on these of PPS. Data on anaemia treatment and diagnosis were not available for each admission, which limits our ability to examine the effects of these factors on recorded anaemia over time. The possibility that the protocol(s) for anaemia management and implementation may vary between transplantation candidates and other RRT groups warrants research attention. Nevertheless, the key results remained unchanged while removing the transplantation group from our main analyses (Results available upon request). Finally, the essentially cross-sectional nature of the data based on each single hospitalization also limited our ability to examine patterns related for example to readmissions.

\section{Conclusions}

We found a significant increase in anaemia recorded as a complication among ESRD hospitalizations in the US following the adoption of PPS. We found ethnic disparities in the recorded anaemia as a complication among ESRD admissions, a gap that was most evident among Native American admissions and that widened for all racial/ethnic groups following the introduction of the PPS. The study demonstrates the potential unintended consequence of measures targeting behaviour in one part of the healthcare system to have a material impact on other parts in terms of both equity and efficiency.

\section{Supplementary information}

Supplementary information accompanies this paper at https://doi.org/10. 1186/s12882-020-02081-4.

Additional file 1: Table S1. ICD9 and ICD10 codes used for identifying study population. Figure S1. Temporal trends (from 2008 to 2016) in the percentage of ESRD admissions with anaemia. Figure S2. Predicted probability of anaemia from the fully adjusted logistic regression model across gender, insurance type, income level, and RRT types over time.

Table S2. The results from main models without weighting variables. Table S3. The sensitivity analysis results from models weighted by HCUP-NIS weighting variable.

\section{Abbreviations}

AHRQ: Agency for Healthcare Research and Quality; CKD: Chronic kidney disease; ESAs: Erythropoiesis-stimulating agents; ESRD: End-stage renal disease; FDA: US Food and Drug Administration; HCUP-NIS: National (Nationwide) Inpatient Sample - Healthcare Cost and Utilization Project; ICD: International Classification of Diseases; PPS: Prospective payment system; RRT: Renal replacement therapies

\section{Acknowledgements}

The data reported here have been supplied by the Agency for Healthcare Research and Quality (AHRQ) and the United States Renal Data System (USRDS). The interpretation and reporting of these data are the responsibility of the author(s) and in no way should be seen as an official policy or interpretation of the U.S. government. I am thankful to Luke Barry for supporting us access to HCUP-NIS data and visualize data.

\section{Authors' contributions}

C.ON. and N.TQ.N designed the study and performed the analyses. N.TQ.N drafted the original paper and visualized data. A.P.M, C.ON. and M.D. reviewed and edited the paper. C.ON. and M.D. supervised the project. All authors approved the final version of the manuscript.

\section{Authors' information}

None.

\section{Funding}

This research is based upon work supported by the Health Research Board research grant RL/2013/16 and Vietnam International Education Development (VIED). This research has received funding from the European Union's Horizon 2020 research and innovation program under grant agreement No 634086 (NEPHSTROM). The material presented, and views expressed here are the responsibility of the author(s) only. The funders had no role in study design, data collection and analysis, decision to publish, or preparation of the manuscript.

\section{Availability of data and materials}

The data that support the findings of this study are available from the Agency for Healthcare Research and Quality (AHRQ) but restrictions apply to the availability of these data, which were used under license for the current study, and so are not publicly available. Data are however available from the authors upon reasonable request and with permission of Agency for Healthcare Research and Quality (AHRQ). Future researchers interested in purchasing and using AHRQ-HCUP databases could visit this website: https:// www.distributor.hcup-us.ahrq.gov/

\section{Ethics approval and consent to participate}

This study was considered exempt by the School Research Ethics Committee/Institutional Review Board at Queen's University Belfast due to the anonymised and publicly available nature of HCUP-NIS data.

\section{Consent for publication}

Not applicable.

Competing interests

The authors declare that they have no competing interests. 
Received: 18 May 2020 Accepted: 27 September 2020

Published online: 06 October 2020

\section{References}

1. United States Renal Data System. USRDS annual data report: Epidemiology of kidney disease in the United States. 2018. https://www.usrds.org/ media/2283/2018_volume_2_esrd_in_the_us.pdf. Accessed 14 Aug 2019.

2. Fishbane S, Spinowitz B. Update on Anemia in ESRD and earlier stages of CKD: Core curriculum 2018. Am J Kidney Dis. 2018;71:423-35.

3. Horl WH, Ertl G. Anaemia and the heart. Eur J Clin Investig. 2005;35:20-5.

4. Atti AR, Palmer K, Volpato S, Zuliani G, Winblad B, Fratiglioni L. Anaemia increases the risk of dementia in cognitively intact elderly. Neurobiol Aging. 2006:27:278-84.

5. Ahmed AT, Go AS, Warton EM, Parker MM, Karter AJ. Ethnic differences in anemia among patients with diabetes mellitus: the diabetes study of northern California (DISTANCE). Am J Hematol. 2010;85:57-61.

6. Robinson BE. Epidemiology of chronic kidney disease and Anemia. J Am Med Dir Assoc. 2006;7:S3-6.

7. Babitt JL, Lin HY. Mechanisms of anemia in CKD. J Am Soc Nephrol. 2012;23: 1631-4

8. Pfeffer MA, Burdmann EA, Chen C-Y, Cooper ME, de Zeeuw D, Eckardt K-U, et al. A trial of Darbepoetin Alfa in type 2 diabetes and chronic kidney disease. N Engl J Med. 2009;361:2019-32.

9. United States Government Accountability Office. End-stage renal disease: CMS Should Monitor Effect of Bundled Payment on Home Dialysis Utilization Rates. 2009. https://www.gao.gov/assets/300/290111.pdf. Accessed 20 Jul 2019.

10. US Food and Drug Administration. FDA drug safety communication: modified dosing recommendations to improve the safe use of erythropoiesis-stimulating agents (ESAs) in chronic kidney disease. 2011. https://www.fda.gov/drugs/drug-safety-and-availability/fda-drug-safetycommunication-modified-dosing-recommendations-improve-safe-useerythropoiesis. Accessed 3 Mar 2019.

11. Weinick RM, Hasnain-Wynia R. Quality improvement efforts under health reform: how to ensure that they help reduce disparities-not increase them. Health Aff. 2011;30:1837-43.

12. Wetmore JB, Tzivelekis S, Collins AJ, Solid CA. Effects of the prospective payment system on anemia management in maintenance dialysis patients: implications for cost and site of care. BMC Nephrol. 2016;17:1-9. https://doi. org/10.1186/s12882-016-0267-x.

13. Norton JM, Moxey-Mims MM, Eggers PW, Narva AS, Star RA, Kimmel PL, et al. Social determinants of racial disparities in CKD. J Am Soc Nephrol. 2016:27:2576-95.

14. Molnar MZ, Ravel V, Streja E, Kovesdy CP, Rivara MB, Mehrotra R, et al. Survival of elderly adults undergoing incident home hemodialysis and kidney transplantation. J Am Geriatr Soc. 2016;64:2003-10. https://doi.org/ 10.1111/jgs. 14321

15. Hung M-C, Ekwueme DU, Rim SH, White A. Racial/ethnicity disparities in invasive breast cancer among younger and older women: an analysis using multiple measures of population health. Cancer Epidemiol. 2016:45:112-8.

16. Sarche M, Spicer P. Poverty and health disparities for American Indian and Alaska native children: current knowledge and future prospects. Ann N Y Acad Sci. 2008;1136:126-36.

17. Centers for Disease Control and Prevention National Diabetes Statistics Report 2020. Estimates of diabetes and its burden in the United States 2020 https://www.cdc.gov/diabetes/pdfs/data/statistics/national-diabetesstatistics-report.pdf. Accessed 24 Aug 2020.

18. Agency for Healthcare Research and Quality. Healthcare Cost and Utilization Project (HCUP) - HCUP National (Nationwide) Inpatient Sample (NIS). 2018. www.hcup-us.ahrq.gov/nisoverview.jsp. Accessed 17 Dec 2018.

19. Waikar SS, Wald R, Chertow GM, Curhan GC, Winkelmayer WC, Liangos O, et al. Validity of international classification of diseases, ninth revision? Clinical modification codes for acute renal failure. J Am Soc Nephrol. 2006; 17:1688-94.

20. Deyo RA, Cherkin DC, Ciol MA. Adapting a clinical comorbidity index for use with ICD-9 administrative databases. J Clin Epidemiol. 1992;45:613-9.

21. Turenne MN, Cope EL, Porenta S, Mukhopadhyay P, Fuller DS, Pearson $J M$, et al. Has Dialysis payment reform led to initial racial disparities in Anemia and mineral metabolism management? J Am Soc Nephrol. 2015;26:754-64
22. FRED Economic Data. Personal consumption expenditures: Services: Health care (chain-type price index). 2018. https://fred.stlouisfed.org/series/ DHLCRG3Q086SBEA\#0. Accessed 27 Sep 2018.

23. Deb P, Norton EC, Manning WG. Health econometrics using Stata. Texas: Stata Press publication; 2017

24. Zakai NA, McClure LA, Prineas R, Howard G, McClellan W, Holmes CE, et al. Correlates of anemia in American blacks and whites: the REGARDS renal ancillary study. Am J Epidemiol. 2009;169:355-64.

25. Khambalia AZ, Aimone AM, Zlotkin SH. Burden of anemia among indigenous populations. Nutr Rev. 2011;69:693-719.

26. Gessner BD. Geographic and racial patterns of anemia prevalence among low-income alaskan children and pregnant or postpartum women limit potential etiologies. J Pediatr Gastroenterol Nutr. 2009;48:475-81.

27. Narva AS, Sequist TD. Reducing health disparities in American Indians with chronic kidney disease. Semin Nephrol. 2010;30:19-25.

28. Thamer M, Zhang Y, Kaufman J, Kshirsagar O, Cotter D, Hernán MA. Major declines in Epoetin dosing after prospective payment system based on Dialysis facility organizational status. Am J Nephrol. 2014;40:554-60. https:// doi.org/10.1159/000370334

29. Khokhar B, Jette N, Metcalfe A, Cunningham CT, Quan H, Kaplan GG, et al. Systematic review of validated case definitions for diabetes in ICD-9-coded and ICD-10-coded data in adult populations. BMJ Open. 2016;6:e009952.

30. Topaz M, Shafran-Topaz L, Bowles KH. ICD-9 to ICD-10: evolution, revolution, and current debates in the United States. Perspect Heal Inf Manag. 2013; 10(Spring):1d.

\section{Publisher's Note}

Springer Nature remains neutral with regard to jurisdictional claims in published maps and institutional affiliations.

Ready to submit your research? Choose BMC and benefit from:

- fast, convenient online submission

- thorough peer review by experienced researchers in your field

- rapid publication on acceptance

- support for research data, including large and complex data types

- gold Open Access which fosters wider collaboration and increased citations

- maximum visibility for your research: over $100 \mathrm{M}$ website views per year

At $\mathrm{BMC}$, research is always in progress.

Learn more biomedcentral.com/submissions 